\title{
Vicente Leñero y el fracaso de su inspector*
}

\author{
Clemens A. Franken K**
}

\section{Resumen}

Luego de exponer brevemente la obra literaria del escritor Vicente Leñero y su lugar dentro de literatura mexicana, se analiza, en su novela posmoderna Los albañiles, la conducta de los personajes sospechosos, la figura y el método de investigación del detective y de sus colaboradores que fracasan en su búsqueda de la verdad, la crítica social y cultural de la sociedad mexicana de los años sesenta y aspectos formales como, por ejemplo, el lenguaje, el narrador y la forma de asimilación.

Palabras clave: Vicente Leñero, Los albañiles, novela policial mexicana posmoderna, asimilación (de Sherlock Holmes y Maigret)

\begin{abstract}
After presenting the literary work of Vicente Leñero and his place in the mexican literature, this article analyzes, whitin his postmodern novel Los albañiles, the behavior of the suspicious characters, the figure and the investigation method of the detective and his collaborators who fail to look for the truth, the social and cultural criticism of the mexican society in the seventies, along with formal aspects, namely the language, the narrator and the assimilation method.
\end{abstract}

Keywords: Vicente Leñero, Los Albañiles, postmodern mexican detective novel, assimilation (Sherlock Holmes and Maigret)

* Este artículo es fruto del Proyecto Fondecyt Regular 2007 Nro. 1071100 "Hibridizaciones, parodias y polémicas con el género policial en la novela latinoamericana".

* Doctor en Literatura. Académico de la Pontificia Universidad Católica de Chile. Investigador Responsable proyecto FONDECYT Regular N¹071100. cfranken@puc.cl 


\section{Introducción}

Este artículo tiene como objetivo, ante todo, el estudio del formato policial de la novela Los albañiles del escritor mexicano Vicente Leñero. Se parte de la hipótesis de que Leñero es un representante importante de una nueva generación de autores mexicanos que une aspectos formales característicos del nouveau roman francés con la novela mexicana tradicional. Se destaca, además, el carácter posmoderno de esta novela que se manifiesta, ante todo, en el fracaso del detective y de sus colaboradores en establecer claramente la autoría del crimen y en las declaraciones contradictorias de los albañiles sospechosos. Finalmente se confirma la pertenencia de esta novela al género negro a través del análisis de su crítica social y cultural.

\section{Obra literaria de V. Leñero y su lugar dentro de la literatura mexicana}

El novelista, guionista, periodista y dramaturgo mexicano Vicente Leñero nace en 1933 en Guadalajara. Luego de estudiar la carrera de Ingeniería Civil en la Universidad Autónoma de México, incursiona, al igual que un Graham Greene o un Gabriel García Márquez, en el periodismo porque sentía una fuerte vocación de escritor. Según revela en una entrevista de 1999, "[e]ntr[ó] a una escuela de periodismo porque pens[ó] que ahí [l]e iban a enseñar a escribir, [él] quería la herramienta, un instrumento para escribir; incluso en [sus] trabajos periodísticos era muy tímido, muy miedoso, [...] dudaba de [la] calidad" (Canales y Fitzmaurice 2) de sus textos. A pesar de considerar siempre la literatura más importante que el periodismo y añorar poder dedicarse exclusivamente a la primera, trabaja por veinte años en la revista Proceso creada por él y un grupo de periodistas cercanos luego del "golpe a Excélsior, que fue un fenómeno político" (Canales y Fitzmaurice 3). ${ }^{1}$ En 1959, publica La polvareda y otros cuentos y dos años después su primera novela La voz adolorida, que consiste, ante todo, en

1 En su novela Los periodistas (1978), Leñero se convierte a sí mismo en "personaje y víctima del golpe echeverrista al diario Excelsior" (Domínguez 273-74). 
el monólogo de Enrique, un enfermo mental, acerca de su vida poco antes de volver al manicomio del cual había huido. Ya estos dos primeros textos literarios de Leñero revelan la presencia de un realismo psicológico en la tradición de F. M. Dostoievski ${ }^{2}$ y otros existencialistas cristianos, ante todo franceses, como, por ejemplo, G. Bernanos, Ch. Peguy y F. Mauriac. ${ }^{3}$ El escritor uruguayo Mario Benedetti, por su parte, ve en la figura de Benjy de la novela The Sound and the Fury, de William Faulkner, "el más seguro antepasado de este Enrique divagador, maníaco, patético" y considera que "ya en esa primera novela Leñero se muestra no como un mero epígono sino como un buen asimilador" que presenta aquí "una insólita variante de suspenso, que consiste en despertar en el lector la curiosidad de saber si la historia que relata el protagonista es realidad o alucinación" (10). En 1963, V. Leñero logra, con la novela Los albañiles, que le valió el Premio Biblioteca Breve de Novela de la editorial española Seix Barral, su primer gran éxito literario de críticas y ventas, la que se analizará más adelante en forma exhaustiva. Esta misma exitosa novela será convertida por Leñero en obra teatral (1970). Otras obras literarias que revelan su talento dramatúrgico son Pueblo rechazado (1968), Compañero (1970), El juicio (1972), La mudanza (1979), La visita del ángel (1981) y El infierno (1991). Con estas obras influyó en el inicio del género documental del teatro en México. Como "católico practicante, seguidor cauto pero persistente de las teologías latinoamericanas de la liberación" (Domínguez 273), Leñero también ha explorado temas católicos, por ejemplo, en la novela El evangelio de Lucas Gavilán (1979) y en el teatro Jesucristo Gómez (1986), mostrando, según el crítico literario mexicano Christopher Domínguez,

sus limitaciones [...]. Entonces Leñero es un escritor simplista y dogmático, como la teología a la que se adhiere. A ese católico al parecer no le fue concedida la gracia que dramatiza a la literatura cristiana moderna: la crisis de conciencia. A diferencia de ancestros ilustres como Bloy, Bernanos o Green, Leñero siempre aparece como un escritor demasiado seguro de sus convicciones, que son pocas y firmes. (Domínguez 273)

El posterior análisis de su novela Los albañiles permitirá confirmar o rechazar esta valoración estético-literaria.

Digna de ser mencionada en esta parte introductoria es, especialmente, la novela Asesinato (1985), por tratarse de una "[r]econstrucción documental del asesinato de los esposos Flores Muñoz en la ciudad de México en 1978, [...], una 'novela sin ficción' que poco tiene que pedirle al Truman Capote de A sangre fría" (Domínguez 272). Según Amelia Simpson, Leñero pretendió

2 Según Josefina Ludmer, por ejemplo, se pueda encontrar similitud entre Don Jesús y el viejo Fedor Karamazov (cfr. A. Simpson 149).

3 Según Christopher Domínguez M., Leñero ha recibido "influencias benéficas de la novela católica, el nouveau roman y el nuevo periodismo" (272). 
en esta novela de formato policial un "grado máximo de objetividad" $(93)^{4}$, basándose exclusivamente en informaciones y documentos a los cuales todo público tuvo acceso. El hecho de que este texto se lee como novela se debe, por una parte, al "tópico sensacional" y, por otra, al "uso de varias técnicas narrativas incluyendo estrategias ficcionales convencionales en la cuarta parte de la novela, sugestivamente titulada 'La novela del crimen"' (Simpson 93). ${ }^{5}$ Por todo eso, Fabienne Bradu considera a la novela Asesinato "una novela policial de considerable envergadura" (citado en Simpson 93).

Finalmente, parece relevante destacar, además, que Leñero transformó varias de sus novelas en guiones cinematográficos como, por ejemplo, El crimen del padre Amaro, una de las películas mexicanas más exitosas. En vísperas de cumplir el autor mexicano los setenta años, le otorgan, en 2002, como reconocimiento de su destacada obra literaria completa, el apreciado y, al mismo tiempo, consagratorio Premio Nacional de Ciencias y Artes de México.

Los críticos literarios insertan su obra en el grupo de autores mexicanos de los sesenta que "se complican y se confunden" (Glantz 212), buscando, ante todo, según Yerko Moretic, "una mayor complejidad estructural" para poder diferenciar mejor "los mundos interiores, explorar motivaciones psíquicas" y presentar "ciertos procesos mentales y afectivos" (14). El mismo Vicente Leñero se compara en este contexto con "el colombiano Manuel Mejía Vallejo, ganador del Premio Nadal 1963" y "el peruano Mario Vargas Llosa, premio Biblioteca Breve 1962", quienes han logrado, por primera vez y al igual que él, colocarse "en primera línea", en el difícil mercado español. De paso, Leñero ubica su novela premiada "dentro de este nuevo panorama al lado y sin desmerecer de la prestigiosa novela de Vargas Llosa La ciudad y los perros” (1964: s/p). ${ }^{6}$ Además, determina su lugar dentro de la literatura mexicana entremedio de

una novela preocupada por valores nacionales e indígenas y [... ] las nuevas corrientes europeas, [...] [aportando] una nueva perspectiva. Por su carácter analítico, por su examen más introspectivo que sociológico de la realidad, por sus hallazgos técnicos y formales en la línea de un Claude Ollier, y más en general de 'nouvelle vague' europea-, Vicente Leñero puede considerarse como el primer novelista de una nueva generación con un estilo nuevo que no por ello pierde contacto con la literatura mejicana tradicional. (1964: $\mathrm{s} / \mathrm{p})$

4 "'maximum degree of objectivity"

5 "sensational topic"; "use of various narrative techniques including conventional fiction-writing strategies in the fourth part of the novel, suggestively titled 'La novela del crimen"'.

6 En la ya citada entrevista de 1999, sin embargo, Vicente Leñero responde al periodista, que coloca su novela Los albañiles a la altura de La ciudad y los perros y Crónica de una muerte anunciada, que no considera su propia novela "así de grande. Hay niveles, yo respeto mucho a mis contemporáneos como los grandes maestros de la literatura contemporánea. Yo pienso que Vargas Llosa, García Márquez, Borges, están en otro nivel, el escritor tiene que tener conciencia de cuáles son sus niveles" (2). 


\section{Mario Benedetti confirma, por una parte, la confesada preferencia de Leñero por el nouveau roman ${ }^{7}$ al constatar "frialdad" e "indiferencia" en Los albañiles}

7 El Nouveau Roman se enmarca en un amplio proyecto de ruptura y renovación que intentará despojar a la literatura de las grandes palabras y de las bellas formas y nociones. Sus precursores son G. Flaubert, M. Proust, F. Kafka, J. Joyce y W. Faulkner. Detrás de todas estas rupturas e innovaciones está el hecho más bien metafísico y cultural de que el discurso occidental tradicional basado en el orden de la razón empezó a tambalearse a partir de la ruptura epistemológica realizada por F. Nietzsche, y que las dos guerras mundiales significaron un gigantesco fracaso histórico de este discurso lógico, provocando un sentimiento general del absurdo existencial. Pero, mientras Sartre y Camus tratan de racionalizar el absurdo, elaborando un humanismo existencialista y una literatura comprometida con él, los representantes de la 'Nueva Novela' le oponen su 'antihumanismo estructuralista'. Para ellos, la literatura y la novela no están al servicio de unos fines morales, sentimentales o ideológicos; escribir no es probar ni seducir, ni siquiera inquietar o despojar al lector de todas las ilusiones para hacerlo tomar conciencia de las injusticias de la sociedad, de las falacias de la civilización o del absurdo de la condición humana. A ellos no les interesa decir verdades, porque no creen en ellas, sino las formas del decir. Sólo les interesan las preguntas. Por eso, renuncian a todo significado y a toda referencia a lo exterior a la literatura misma. Como dice Robbe-Grillet, el portavoz de esta generación, en su ensayo "Para un nueva novela": "El mundo no es significante ni absurdo. Simplemente es.' Estamos, por lo tanto, ante una literatura amimética y radicalmente antirepresentativa que rompe con la larga tradición literaria de la escritura 'realista' con su discurso reproductor de sentido. Robbe-Grillet pretende solamente crear nuevas realidades verbales, recorriendo la superficie de los objetos, respetando su incertidumbre, su inconsistencia metafísica o su angustiosa contundencia (cfr. Patricia Martínez).

Dado que la materia que propone la nueva novela no es ordenada, provocando en el lector la misma sensación de extrañeza ontológica que experimenta el escritor y el hombre en general frente al mundo, al lector le corresponde estructurar la materia y darle un sentido. De esta forma, la novela nueva se independiza del autor y creador, formando un sistema cerrado y autosuficiente, un cosmos sin implicaciones personales, afectivas o históricas. Consecuentemente, los teóricos literarios del estructuralismo francés declararon la muerte del hablante individualizado y de la conciencia individual que se difumina frente "al sistema como totalidad" (P. Ricoeur).

Dos consecuencias inmediatas son la novela antihumanista y la novela formalista. La última se caracteriza, en primer lugar, por la desaparición del personaje y de la psicología individual como centro organizador de la ficción, la supresión de la lógica de las acciones como factor de estructuración del relato. En vez de héroes, hay seres anónimos, neutros, indefinidos, de oscuras motivaciones y obsesiones fútiles. Tampoco hay un punto de vista único que es desplazado por una multiplicidad de perspectivas. En segundo lugar, el desorden cronológico se convierte en un rasgo estructural característico de la novela formalista, con el consecuente aniquilamiento de la anécdota. A la progresión convencional de la trama de la novela se sustituye la yuxtaposición de secuencias inconexas, se subvierte la ordenación lineal del tiempo y a menudo se aproxima al grado cero de narratividad. En tercer lugar, hay un hiperdesarrollo de la coordenada espacial, es decir una novela formalista esencialmente descriptiva en la que lugares y objetos cobran una inusitada relevancia mientras que personajes y acciones son relegados a un plano meramente tangencial. En cuarto lugar, hay una atención especial a la dimensión técnica de la novela: p. e. procedimientos de intertextualidad; microrrelatos que reproducen la trama principal en el interior de la novela; utilización de figuras abstractas, geométricas, aritméticas y/o gramaticales; cohesión entre el contenido argumental y su distribución formal, pretendiendo una perfecta correlación entre forma y contenido. Se rechaza, ante todo, la metáfora tradicional ya que ella es considerada como el principal artífice de la visión antropomórfica que reorganiza las relaciones entre el individuo y el mundo a través de los parámetros estéticos o afectivos que recomponen el mundo en un orden esencialmente humano. Robbe-Grillet y otros nuevos novelistas como, por ejemplo, Michel Butor, Robert Pinget, Claude Ollier, pretenden reemplazarla intentando restablecer las distancias entre el hombre y las cosas, liberándolas de toda interferencia humanizante. 
y reconocer "la encandilante maestría del novelista para armar y desarmar su mundo ante la estupefacta mirada del lector." Por otra parte, no estima muy lograda la pretendida "'pintura realista de un medio obrero", la que considera más bien "como una lejana y congelada presencia" (10).

También otros críticos literarios celebran el "virtuosismo" y la "cabeza fría para planificar y organizar el tumulto de planos narrativos" (R. C. s/p) de Vicente Leñero, su "mente matemática" y su "conocimiento profundo del tiempo del realismo" que "hacen de sus novelas emocionantes arquitecturas portátiles" (Domínguez 272). Sin embargo, al mismo tiempo, critican "la convencional y algo barata psicología de los personajes" (R. C. s/p) o consideran su obra literaria "recargad[a] con materiales impropios", hecho que convierte, por ejemplo, la novela Los albañiles en "una dispareja novela" (Concha 7). Resumiendo las voces de los estudiosos literarios respecto al (por Leñero) pretendido lugar entremedio entre nouveau roman ${ }^{8}$ y literatura mexicana nacional e indigenista tradicional, se puede afirmar que la gran mayoría percibe más nítidamente la presencia de los rasgos característicos de la nueva novela francesa y, algo menos lograda, la descripción realista del mundo obrero de los albañiles. Cabe destacar, finalmente, que este intento de síntesis de vanguardia formal y realismo tradicional le valió a Vicente Leñero, de parte de la generación del 68, "una pronunciada inclinación" (Prieto 108) por su obra literaria.

\section{Análisis del formato policial y de los albañiles sospechosos}

La cercanía formal de Leñero a la nueva novela francesa se revela también en su inclinación hacia el género policial. Al igual que en muchas novelas de Robbe-Grillet, Butor, Pinget y Ollier, también en el caso de Los albañiles de Leñero se trata de

una novela policial: en el cuarto de baño de uno de los apartamentos de una obra en construcción, un peoncito llamado Isidro, quince años, encuentra el cadáver de don Jesús, el sereno, un viejo corruptor y corrompido. La novela es el desarrollo de la investigación policial a que da lugar aquella muerte. El inspector Munguía va interrogando a todos los posibles implicados, [...]. Con el pretexto de la encuesta policial y de los correspondientes testimonios y declaraciones, Leñero propone tres enfoques que aparecen ligados, mezclados, superpuestos, nunca demasiado explícitos. Por un lado, está el diálogo entre inquisidor e interrogados; por otro, está lo que cada interrogado piensa (o se propone declarar); y, por último, está

8 Según Christopher Domínguez M., la novela La gota de agua, escrita veinte años más tarde que Los albañiles, "es una fina burla de la vieja 'nueva' novela francesa" (272). Si fuese así, significaría que $\mathrm{V}$. Leñero se distanció más tarde de su temprano entusiasmo por el nouveau roman 
lo que el inspector opina sobre el caso y también lo que él imagina que cada interrogado piensa. (Benedetti 10)

Además, cada sospechoso declara su inocencia y acusa a otro sospechoso de haber matado al viejo don Jesús. Por ejemplo, según el joven Isidro, -quien "descubrió el cadáver en el baño del departamento 201" (LA 10) un martes a primera hora en el lugar del trabajo, es decir, de la construcción de un nuevo edificio, del cual el viejo don Jesús abusó como asímismo de su novia Celerina-, su compañero de trabajo Jacinto odiaba al viejo sereno y "[s]e le metieron los endemoniados. [...] jJacinto mató a Jesús!" (LA 45). Más adelante aún declara que vio cómo Jacinto mató a don Jesús y le robó dinero (cfr. LA 154). El maestro Jacinto, estrecho colaborador y hombre de confianza del chapo, es decir del capataz Álvarez, por su parte, habla de la posibilidad de que justamente este amigo suyo, quien mantenía una relación amorosa con la joven esposa del viejo sereno y había jurado matarlo, lo hiciera con un "fierro" (LA 221) cuando don Jesús el lunes en la tarde estaba en el baño del segundo piso. Curiosamente, al comienzo de la novela y delante del joven ingeniero Federico Zamora, el maestro Álvarez defiende a don Jesús de las acusaciones del plomero Sergio García, llamado por el apodo burlón 'el cura' por haber estado algunos años en un seminario intentando en vano de convertirse en sacerdote. A este hermano de la Celerina, el que, al igual que Álvarez, había amenazado al viejo sereno con matarlo por haber abusado de su hermana, Álvarez lo acusa indirectamente al decir de él que "odiaba a todos los albañiles, incluyendo [...], desde luego, a don Jesús. Tipo raro. No metería la mano en la lumbre por él” (LA 71). Por su parte, Sergio García no parece acusar a nadie. Sí lo hace el joven ingeniero Federico Zamora, alias 'el Nene', del cual todos los albañiles, don Jesús incluido, se burlan por ser incapaz de reemplazar a su padre, a quien todos estimaron. Según el narrador omnisciente presente en esta novela, Federico le tenía asco a don Jesús y "necesitaba hacer algo, y pronto: pegar la carrera o plantarse por primera vez en su vida para aguantar la embestida y vaciar sobre un loco degenerado la ira acumulada durante semanas y semanas de oírse nombrado con un apodo, menospreciado por hombres de condición inferior [...]" (LA 87). En defensa propia, Federico piensa acusar a Jacinto de haber matado a don Jesús.

\section{El inspector Munguía, sus colaboradores y método de investigación}

Si se agrega a estas diferentes y contradictorias versiones de los acontecimientos, las acusaciones mutuas entre los sospechosos y las deducciones, conjeturas e imaginaciones del inspector, no sorprende que al final reina en la cabeza del inspector Munguía una confusión tan grande que no logra resolver el enigma. A pesar de su honesto empeño, Munguía, al igual que el detective Lönnrot del cuento borgeano "La muerte y la brújula", fracasa en su "búsqueda, que sabe infinita, de la verdad" (Domínguez 273) que resulta "algo inasible". Con este 
desenlace posmoderno y concordante tanto con los autores del nouveau roman como con Borges y el García Márquez de Crónica de una muerte anunciada (1981), que significa de hecho una inversión del modelo policial clásico tanto de la vertiente de enigma como de la negra, Leñero parece decirnos que a la realidad en su profunda complejidad podemos acercarnos solamente "mediante sucesivas aproximaciones espurias" y que "cada mexicano tiene y despilfarra su verdad, pero que la verdad (o la culpa) definitiva no existe" (Benedetti 10). Al igual que García Márquez, acusará en dicha novela a todo el pueblo por su falta de solidaridad con Santiago Nasar, el inspector Munguía de Leñero reconoce a casi todos los albañiles como responsables de la muerte de don Jesús.

En la última página de Los albañiles, sin embargo, se remedia la confusión y falta de resolución del enigma en la anulación del crimen y la aparente locura de Munguía, pues las últimas líneas de la novela dan atisbos de que don Jesús aún vive:

Caminó [el inspector] toda la noche y a las siete de la mañana llegó a la esquina de Cuauhtémoc y Concepción Béistegui. Largo rato contempló el edificio desde la acera oriente. [...] Empujó la puerta de fierro: tras ella, a no más de cinco pasos de distancia, estaba un hombre envuelto hasta la cabeza con un sarape. [...]

-¿Buscaba a alguien?

Munguía avanzó tres pasos. El hombre se levantó.

-¿Buscaba a alguien?

- ¿Es usted el velador?

-Si -dijo el hombre-. ¿Qué se le ofrece?

Munguía lo miró de arriba abajo.

-Nada -Avanzó un paso más. Sonrió-. Nada... - Y le puso una mano en el hombro. (LA 249-50) ${ }^{9}$

El concepto de la realidad parece así en Los albañiles como fruto de la imaginación, algo que ya el filósofo alemán romántico Schopenhauer postuló en su obra fundamental El mundo como voluntad y representación (1816), dejando profundas huellas en muchos escritores como, por ejemplo, J. L. Borges y Th. Mann.

Del inspector Munguía, sin embargo, no sabemos solamente que fracasó en la búsqueda de la verdad, sino que conocemos algunos pocos datos de su personalidad. Si bien hace su aparición en el primer capítulo apenas se ha producido el asesinato, es incorporado al relato sin ninguna referencia, más que la

9 En una lectura alegórica, se podría interpretar tal vez al inspector Munguía como uno de los discípulos de Emaús, que, después de un largo caminar, finalmente reconoce al Jesús resucitado y transformado. Una lectura alegórica se justifica, además, si se toman en consideración otros factores de la novela: en primer lugar, el hecho de que los albañiles ejercen, al igual que el Jesús histórico, la profesión del carpintero; luego el hecho que hay una seria de acusaciones en contra de don Jesús que pueden ser falsas, al igual que aquellas contra el Jesús histórico; y, finalmente, hay diferentes disculpas de la muerte de don Jesús que evocan aquellas históricas de Poncio Pilato, Caifás y Herodes. 
de llevar "una corbata a rayas" (LA 16). A tal punto llega la falta de información sobre el encargado del caso, que sólo en el undécimo y último capítulo de la novela se reconoce con el apellido de Munguía. Como enviado del ministerio público viene acompañado de otros policías, Valverde, Dávila, Suárez y Pérez Gómez. Munguía se presenta como un hombre poco sociable y más bien solitario, tanto con sus compañeros hombres como con las mujeres. Los diálogos con sus colaboradores son escasos y todos referidos al caso de la muerte de don Jesús, e incluso, cuando los colegas lo invitan a formar parte del juego de dominó que se ha estado efectuando durante estos cuatro días que dura la investigación, Munguía no se niega solamente, sino que ni siquiera otorga una respuesta: "Entró Dávila. ¿No juegas un dominó? Munguía se aflojó el nudo de su corbata a rayas y miró a Dávila, pero no contestó" (LA 225). No es sólo en esta instancia que prefiere apartarse de la compañía, pues al invitarlo Pérez Gómez a distraerse a una casa de prostitutas, a pesar de que en primera petición lo acompaña, pronto se siente incómodo y abandona el lugar de diversión. Pese a la impresión de indiferencia a la que pueden referir estos hechos, el hombre de la corbata a rayas no es una persona indiferente a la justicia y la verdad. Munguía está ansioso por descubrir quién asesinó a don Jesús y cuando ve que se acerca el plazo para dilucidar el caso, es decir, el viernes en la tarde, pide aplazar la fecha por lo menos por un día, con el fin de poder llegar a la verdad, pero su intento "es inútil" (LA 240).

Sabemos también de los conocimientos psicológicos de Munguía y conocemos su método de investigación, ante todo, su forma de interrogar a los sospechosos. Munguía, al igual que el comisario parisino Maigret, sabe que

[e]l investigador debe conocer, en primer término, la índole de la materia humana sobre la cual actúa; porque el mayor conocimiento del mecanismo psíquico individual lleva, como de la mano, al perfeccionamiento de la investigación. [...] [Luego,] [e]l interrogador debe adaptarse a la personalidad del interrogado. Si éste, por ejemplo, es un exhibicionista, adoptará la técnica de subestimar sus capacidades. Tal táctica pretende conseguir que el delincuente, por un deseo inconsciente de poner de relieve su personalidad, de demostrar su habilidad propia, concluya, fatalmente, dados algunos detalles comprometedores. (LA 163-64)

Además de estos conocimientos psicológicos, hay que destacar en Munguía su cualidad de saber escuchar, que usa como técnica con los sospechosos, reconociendo que no hay "nada como el silencio, [...], para quebrantar la firmeza de ciertos delincuentes" (LA 164). Es tal la capacidad para escuchar que posee Munguía que el lector a veces se olvida de que está presente en la escena y que las historias de cada trabajador se cuentan producto del interrogatorio que el inspector está efectuando. Si bien es un hombre que sabe poner atención a los relatos de los posibles involucrados en el asesinato, al momento de inquirir información en sus narraciones hace notar su presencia al guiar el diálogo hacia lo primordial, extrayendo sólo lo esencial de estos. Por ejemplo, 
es insistente cuando cree finalizada la conversación con Patotas, otro de los albañiles: Munguía, "[e]l hombre de la corbata a rayas, miró los zapatos de Patotas, reventados por sus pies. Tronó los dedos al decir: -Está bien, con eso tengo; después hablaremos" (LA 48); y ante la negativa de Patotas de retirarse del lugar, Munguía vuelve a insistir con vehemencia: "lárguese - gritó el hombre de corbata a rayas" (LA 51), logrando el desalojo de Patotas del lugar y comenzando un nuevo interrogatorio con el joven Isidro. No obstante, su afán por rescatar lo primordial de cada discurso, en otras instancias se vuelve más inquisidor; al tener más sospechas de un sujeto, opta por una mayor minuciosidad del relato de quien interroga. Este estilo indagador se ve reflejado, por ejemplo, en la interrogación que le hace a Sergio García, el plomero que había estado en el seminario y de quien más sospecha, pues el viejo Jesús había abusado de su hermana menor de catorce años, Celerina. El inspector opta por el detalle de su historia diciéndole: "Vámonos con calma, amigo García. Quiero saber todo lo que usted hizo el lunes" (LA 170) recién pasado. En el capítulo cinco, dedicado exclusivamente a la interrogación de Sergio García, el inspector Munguía trata de arrinconarlo, atacándolo con sus cuestionamientos e insinuaciones respecto a su estadía en el seminario y condición como católico practicante. En forma odiosa, obliga a García a interpretar la parábola del buen Samaritano en su relación con don Jesús, tal forma que el plomero siente que el inspector se burla de él (cfr. LA 107). Esta interrogación insistente, rápida, ágil e inquisidora de Munguía, que algunos expertos llaman "interrogatorio-schock", trata, según expone Munguía, de "provocar la confusión en el plano emotivo, conduciendo, por ejemplo, al presunto culpable al lugar del delito, invitándolo a pensar en su familia [...] para quebrantar la resistencia de los detenidos y provocar su confesión" (LA 169).

Otro método de investigación relevante de Munguía es la observación. Al igual que su colega inglés Sherlock Holmes, parte de la observación para obtener, posteriormente, ratificaciones a partir del análisis de las pistas halladas en el lugar del crimen. Al momento de entregar la supuesta resolución del enigma, en donde todos son culpables, se demuestra que Munguía, a pesar de no concentrarse generalmente tanto en la observación como en la interrogación, ha puesto atención a todos los detalles que pueden ser pistas para encontrar al culpable, por ejemplo, el análisis de las manchas de sangre en la prenda de Isidro, las huellas dejadas por Álvarez o los mismos pelos que a éste le habría arrancado don Jesús en un supuesto forcejeo por salvarse. No sorprende, por tanto, que uno de sus compañeros se refiera a él utilizando el apelativo de Sherlock Holmes, debido a que logra enterarse de todo lo que va aconteciendo en su entorno, incluso llegando a descubrir el uso que sus compañeros hacen de la violencia en uno de los interrogatorios (cfr. LA 226).

La observación lo lleva, luego e inevitablemente, a efectuar ciertas deducciones, otro método infaltable de una buena indagación policial. Cuando Munguía interroga a Isidro, consigue inculparlo explicando al lector cómo, mediante la deducción, llegó a su supuesta culpabilidad: 
Si un inculpado presenta sobre sus vestidos manchas del grupo II y este individuo pertenece al grupo II no puede afirmarse, lógicamente, que las manchas no procedan de su propio cuerpo; pero si el sospechoso pertenece al grupo III resultará evidente que las manchas de sangre proceden de una persona distinta. Un hombre amanece muerto; su sangre pertenece al grupo IV; sobre una prenda del inculpado se aprecian manchas del grupo IV precisamente; la conclusión lógica será que existen muchas probabilidades de que el propietario de esa prenda encontrada en casa de Pachita sea el autor del crimen. (LA 232)

Sin embargo, según las reflexiones del propio inspector Munguía, el razonamiento típico en las investigaciones criminales "no es un razonamiento deductivo, sino un razonamiento por analogía" (LA 235), basado, por ejemplo, en causas célebres. "La formación del criminalista supone lo que Conan Doyle llamaba una amplia erudición en materia sensacionalista” (LA 235). Por eso, Munguía recomienda no confiar tanto en la evidencia o la lógica corriente, dado que los criminales se preocupan poco de la lógica y realizan a menudo actos absurdos. Siguiendo luego a Georges Simenon, el creador del comisario parisino Maigret, da especial énfasis en los "indicios de orden psicológico" (LA 235), a cuyo profundo conocimiento, en el caso de Munguía, ya nos hemos referido más arriba.

A base de sus observaciones, deducciones y conocimientos de causas criminales, Munguía hace uso de la suposición y crea hipótesis y conjeturas. Por ejemplo, en la figura de Sergio García hay algo que lo lleva, en un primer momento, a pensar en él como el culpable. Sin embargo, poco a poco, estas suposiciones van siendo descartadas. En este mismo caso, páginas más adelante ya se observa cómo desecha esta hipótesis de acuerdo a lo que va conociendo de cada albañil en sus interrogatorios: "[...] había que ir retirando las sospechas contra el plomero y pensar en cualquier otro albañil que tuviera más razones para matar al velador" (LA 81). Sin embargo, al desechar esta determinada hipótesis, comienza a establecer otras. De esta forma, toda la novela, y especialmente el último capítulo, está llena de conjeturas imaginadas tanto por el inspector Munguía, como también por muchos albañiles y los compañeros del inspector.

Su relación con estos últimos no es muy buena. Más arriba ya se hizo alusión al hecho de que no les contestaba sus preguntas ni jugaba dominó con ellos. Parece que el inspector Munguía se distingue de sus colaboradores no solo socialmente, por algo es el hombre que lleva corbata lo que podría insinuar su pertinencia a la clase social media alta, sino también a nivel ético, dado que a diferencia de sus colaboradores busca seriamente resolver lo antes posible el caso mientras que estos no muestran ningún afán especial en colaborar en esta búsqueda de la verdad y justicia de su jefe sea porque él no se lo permite o sea porque prefieren pasarlo bien escapando del tedio a través del juego de dominó. Ellos, por otra parte, se muestran muy condescendientes con su jefe. 
Pérez Gómez, por ejemplo, delante de las prostitutas del prostíbulo, lo califica de modesto e inteligente que "[n] o deja títere con cabeza" (LA 249). Poco antes le había ofrecido todo su apoyo, cuando pretenden quitarle el caso por demora de la resolución, e, incluso, le expresó su admiración por la técnica que usa en sus investigaciones. Sin embargo, esta es mera apariencia de lo que realmente piensa, pues, apenas tiene la oportunidad de comentarlo con otro de los detectives, reconoce su ineficiencia en el trato con los interrogados y lo descalifica como "loco" (LA 53). Así, deja en evidencia el doble estándar y la duplicidad de uno de sus colaboradores que representa 'pars pro toto' también la conducta ética cuestionable de todos los compañeros de Munguía.

\section{Crítica social y cultural}

La convivencia de los albañiles no es solamente llena de duplicidad, sino también de mentira, fariseísmo y corrupción. Leñero nos revela una "visión terriblemente pesimista" de una parte de la realidad social mexicana, "sin enjuiciamiento para nadie en particular" y "sin enunciación ideológica ni mensaje social" (Benedetti 10). De hecho, la relación de los albañiles entre ellos mismos parece estar caracterizada, ante todo, por el odio. Según el joven ingeniero Federico, los auténticos campesinos del sur son buena gente porque aún no está maleada y desadaptada como los albañiles que se fueron a la gran ciudad por la necesidad de ganar más dinero. "La realidad que encuentran en la capital es totalmente opuesta a la que habían imaginado. Viene entonces el desengaño y la frustración. [...] [Por eso,] se vuelven hipócritas y desleales. Es natural que se odien entre ellos mismos porque, como en un espejo, cada albañil ve reflejado en su compañero su propia frustración" (LA 72). Esta odiosidad, al igual que la "ausencia de lazos solidarios [...], corrupción, violencia e irresponsabilidad" (R. C. s/p), tiene que ver, según Leñero, con la desigualdad, la falta de oportunidades y la explotación de ciertos grupos que detentan el poder, frente a lo cual aquellos que buscan oportunidades están dispuestos a desempeñar cualquier tarea, incluso olvidando los requisitos mínimos de un trabajo digno. Por ejemplo, cuando se piensa en Federico como autor del crimen contra don Jesús, se cree que fue en defensa propia, para evitar que el viejo sereno le pegase un martillazo en la cabeza, haciendo uso luego del mismo instrumento para el posterior asesinato del velador. Sin embargo, el narrador entrega una explicación socio-psicológica del actuar impulsivo de don Jesús, lo que lo habría motivado a un posible ataque contra Federico:

"Fue la explosión de un pobre viejo degenerado, loco, infeliz, enfermo, que se pasó la vida corriendo el país de pueblo en pueblo; tantas veces explotado por quienes le daban trabajo por unos días y se negaban después a pagarle o le pagaban apenas unos cuantos pesos apenas suficientes para mal comer durante toda la semana o el mes que transcurría antes de lograr encontrar un nuevo trabajo" (LA 88). 
En esta escena, como en muchas más de la novela analizada, destaca Leñero el potencial de violencia ${ }^{10}$ presente en esta pequeña comunidad de albañiles que se caracteriza por valores viriles, o mejor dicho, machistas. Permanentemente, acontecen actos violentos, como, por ejemplo, el empujón que da Jacinto a Celerina, la hermana de Sergio García, el plomero con el apodo 'el cura', que no tiene ni el valor ni la fuerza para hacerse respetar y menos para vengarse. De él hasta el viejo don Jesús se burla, al igual que su cuñado, el improductivo y flojo marido de su hermana Concha, la cual también se toma el derecho de cuestionarle a Sergio su virilidad, insinuando que es un cobarde 'maricón', al igual como lo hace su inútil marido (cfr. LA 174-75). Este, por su parte, maltrata a su esposa, entre otras cosas, recordándole sus deberes como madre de un lactante, para que él pueda dormir tranquilamente su siesta. Otra crítica al machismo mexicano expresa Leñero a través de una señora que insulta a un prepotente chofer de bus que no tolera su ataque y la hace bajar violentamente del bus.

Tensa y violenta es también la relación entre los albañiles y el joven ingeniero Federico, llamado por ellos con el apodo 'el Nene'. A diferencia de su responsable y esforzado padre, Federico no estudió mucho en la universidad, comprándose las pruebas como buen 'hijo de papá'. No sorprende, por tanto, que no esté capacitado a reemplazar a su respetado padre en forma digna y que los albañiles no estén dispuestos a pagar por su prepotencia y sus mentiras para camuflar su ignorancia profesional. Especialmente Jacinto siente muchas ganas de "pegarle fuerte” (LA 206), pero Álvarez le aconseja vengarse con inteligencia.

La violencia se une al sexo en dos momentos. En primer lugar, en la violación de la joven Celerina por parte del viejo don Jesús, que revela con este acto depravado que fue probablemente un error haberlo dejar salir del manicomio. En segundo lugar, el maestro Álvarez le quita a don Jesús su más joven esposa, provocando naturalmente la rabia y frustración del sereno, y futuros encontrones.

Otro fenómeno cultural digno de mencionar, porque comprueba que la mirada de Leñero está insertada en la cultura mexicana con sus mitos paganos y cristianos respectivos (cfr. Simpson 92), es la forma en que los albañiles viven su fe, que consiste, ante todo, en una profunda devoción a la Virgen del Sagrario, pero que no logra determinar mucho la conducta ética de los fieles. Según el maestro Jacinto, por ejemplo, "no se puede mentir. Menos cuando uno pone de fiadora a la Virgen del Sagrario. Con ella hay que andarse con cuidado" (LA 209). Ya le pasó una vez, cuando se hizo protestante y la Virgen, según él, lo castigó enviándole varias "desgracias". Desde ese entonces, Jacinto se cuida y pone "por delante a la virgen” (LA 211). Su fuerte devoción mariana, tan típica

10 Según Amelia Simpson, se puede ver en don Jesús, la víctima, "un sacrificio simbólico para bajar el odio acumulado dentro de un pequeño grupo que representa la clase trabajadora urbana de la sociedad mexicana" ("a symbolic sacrifice to release the accumulated hatred within a small group representing urban, working-class Mexican society") (90). 
para la religiosidad popular mexicana con su devoción de la Virgen de Guadalupe, no le impide, por ejemplo, robarle mucho material de construcción al ingeniero Federico Zamora para la secreta construcción gruesa de su casa, con la ayuda del maestro Álvarez y otros albañiles. En este episodio, aflora también una clara crítica tanto a los sacerdotes católicos como a los protestantes. A los primeros, por enseñarles a sus feligreses que los protestantes "son enviados del demonio para condenar a las almas", y a los segundos por 'comprar' en cierta medida a los fieles católicos débiles en su adhesión a la Iglesia católica regalándoles "un tambache así de ropa y un boleto para ir al cine" (LA 210). Sin embargo, en la persona del 'cura' Sergio García, Leñero parece mostrarnos un católico mexicano bastante convincente.

Finalmente, se puede constatar una fuerte crítica no sólo a determinados fenómenos culturales, sino al país en su totalidad y al gobierno en especial. Efectivamente, ya al comienzo de la novela, el narrador critica el afán de mostrarse como una nación que no les pertenece, olvidando sus aspectos negativos, optando por sepultarlos y renegarlos, en vez de reconocerlos y buscar una solución a ellos. De esta forma, se pretende presumir algo que no se es, incluso, a nivel de los medios de comunicación masiva:

Lo que no dicen los periódicos pero es tan cierto como que hay hambre en el mundo es que el gobierno está de acuerdo con los gringos en lo de las bombas atómicas: con temblores y aguaceros resulta muy fácil acabar con todos los pobres de México y de donde sea, así piensan limpiar las ciudades, es lo más sencillo; esos canijos no se detienen ante nada: con tal de presumir de una ciudad limpia se hacen aliados del mismo diablo y arrasan parejo. (LA 31)

La crítica social de Leñero culmina, además, en recalcar, en varias ocasiones, la desesperante pasividad del gobierno mexicano frente a la pobreza y la explotación.

\section{Aspectos formales}

Desde el punto de vista formal, ya se destacó con respecto a Los albañiles que "ante tantos personajes hablantes en primer plano, el autor no aparece jamás con sus propias opiniones, [...] con lo que da un buen ejemplo de objetividad a esos novelistas que a cada rato entran personalmente en escena" (Concha 7). De esta forma, Leñero cumple un postulado sumamente importante para Robbe-Grillet y otros nuevos novelistas franceses. ${ }^{11}$ Con relación al narrador, se presenta, en primera instancia, un narrador omnisciente que conoce todos los aspectos de la historia y de los personajes y presenta la situación inicial, permitiendo el primer acercamiento con las actividades de los protagonistas:

11 Los críticos literarios alemanes, no en vano, hablan, en el caso del nouveau roman francés, de una "novela objetiva" ("Dingroman") 
"Lo encontró Isidro, el peón de quince años que, cargando un bote de mezcla, arrastrando una carretilla, enrollando la manguera, corriendo a traer el refresco [...] aparecía y desaparecía como un fantasma urgido por los gritos de Jacinto" (LA 7). Sin embargo, en los capítulos dedicados a la supuesta confesión de cada uno de los albañiles, el narrador pasa a ser un narrador personaje, pues son los mismos protagonistas los que cuentan su historia y se defienden de ser el posible responsable de la muerte de don Jesús. Leñero usa, entonces, una focalización múltiple o focalización interna variable, intercalando permanentemente narraciones directas con indirectas. Por eso, para el lector confundido, apenas es posible reconocer que estas confesiones, que más bien parecen relatos independientes, se dan en el marco de un interrogatorio que se encuentra más bien escondido, pues prácticamente en ningún momento se plantean preguntas que vayan guiando el relato de los albañiles. Ya se mencionó más arriba que recién en el último capítulo se sabe claramente el nombre del inspector que está a cargo de una investigación sobre el asesinato del viejo don Jesús. El lector debe, por eso, obligadamente convertirse en un detective frente al texto, al igual que antes el autor frente a la caótica e impenetrable realidad del mundo, porque depende de su habilidad descifradora si logra distinguir cuándo, dentro del mismo monólogo de Munguía en el último capítulo, éste comienza a culpar a otro de los albañiles, sin hacer referencia al cambio de referente que efectúa, comprendiéndolos a todos como si fueran una sola persona. Esta distinción es difícil pero posible, pues el monólogo final y explicativo de Munguía, tan apreciado por Sherlock Holmes, alude a cada una de las historias anteriormente referidas por los personajes, lo que permite identificarlo a medida que se nombra algún rasgo que ya se entregó con anterioridad.

La identificación de los personajes es también posible por el hecho de que cada uno usa un lenguaje propio, aunque todos "siguen empleando un lenguaje rural, salpicado de palabrotas nada indispensables. El autor, en homenaje a un supuesto realismo, no tiene impedimento en transcribirlas fielmente, con lo cual, [según Concha], favorece menos al realismo que al mal gusto" (7). Sin embargo, más adelante, este mismo crítico literario chileno le concede que "escribe en una forma caudalosa, fluente, vital", usando "palabras propias del habla cotidiana de Méjico, de significación desconocida en Chile, tales como chamba (trabajo), bote (cárcel), torugo (tonto) cuate (mellizo) trole (ebrio), etcétera" (7). Este lenguaje cotidiano de los albañiles usado por Leñero, sin embargo, permite que cada personaje de la novela hable auténticamente de su experiencia y hace posible encontrar ciertas marcas de su registro de habla que permiten pensar en el mundo de la construcción y el ambiente citadino de un edificio en construcción. Por ejemplo, el vocabulario grosero del cortejo de los albañiles para con Celerina y el deseo sexual que provoca en ellos, llega a su punto cúlmine con la violación de don Jesús a la muchacha, cuando le dice groseramente que grite lo que quiera, pues "nadie escuchará ese grito, gatita brava; grita todo lo que quieras, canija escuincla, nadie te va a oír [...]” (LA 165). 


\section{Conclusión}

Podemos resumir, finalmente, que Vicente Leñero asimila en esta novela posmoderna tanto elementos de la novela policial clásica de enigma (alusiones a la figura de Sherlock Holmes, su método de investigación, el monólogo final explicativo, etc.) como de la novela clásica negra (lenguaje coloquial, violencia y sexo, etc.), logrando mezclar, en forma exitosa, aspectos formales de la nueva novela francesa con un realismo que da cuenta de la realidad mexicana.

\section{Bibliografía:}

Benedetti, Mario. "La Realidad Mexicana en el Pantógrafo de Leñero". La Mañana, Montevideo, 22 de enero de 1965. 10.

Canales, Santiago / Fitzmaurice, Alejandr. "Vicente Leñero: un escritor universal". La Revista Peninsular, Nro. 521 (15 de octubre de 1999). 1-4. (http://www.larevista.com.mx/ed521/5216.htm)

Concha, Edmundo. "Vicente Leñero: 'Los Albañiles". El Mercurio, Santiago, 28 de diciembre de 1966. 7.

Domínguez M., Christopher. Capítulo "Leñero". Diccionario crítico de la literatura mexicana (1955-2005). México (D.F.): Fondo de Cultura Económica, 2007. 272-74.

Glantz, Margot. Esquince de cintura. Ensayos sobre Narrativa mexicana del siglo XX. México (D.F.): Consejo Nacional para la Cultura, 1994.

Leñero, Vicente. Los Albañiles. $10^{a}$ reimpresión. México (D.F.): Planeta / Seix Barral, 2006.

"Los Albañiles". El Mercurio. Santiago, 22 de noviembre de 1964. s/p.

Moretic, Yarko. “'Los Albañiles' de Vicente Leñero”. El Siglo, 5 de marzo de 1967.14.

Prieto, Francisco. "Constructivistas e iconoclastas en la generación del 68". Literatura mexicana hoy. Del 68 al ocaso de la revolución. Por Karl Kohut (ed.). 2da ed., Frankfurt am Main / Madrid: Vervuert / Iberoamericana, 2005.107-118.

R. C. "Un Virtuoso Mexicano". El País, Montevideo, 28de marzo de 1965. s/p.

Simpson, Amelia. Detective Fiction from Latin America. London y Toronto: Associated University Press, 1990. 